\title{
O Principio Constitucional da Igualdade Perante a Lei e o Poder Legislativo
}

\section{SeAbra Fagundes}

1. Ainda quando o princípio da igualdade jurídica possa parecer, na literalidade da sua enunciação pela Constituição da República, (1) apenas endereçado ao aplicador das normas legislativas - o administrador ou o juiz - o certo é que, pelas razões superiores que o inspiram e pelas finalidades a que se destina, é endereçado, também, ao legislador. Para melhor compreender a exatidão dessa verdade, basta atentar em que $\alpha$ cânone da igualdade perderia por inteiro a sua significação, como princípio expresso nas Cartas Políticas dos Estados democráticos, se o Poder Legislativo o pudesse desconhecer. As desiguaddades não nasceriam eventualmente de atos administrativos ou de sentenças, mas se multiplicariam a critério do órgão legiferante, exatamente aquêle que, pelo largo alcance dos seus atos quanto às pessoas, maior número de situações pode afetar com tratamento discriminatório. O princípio resultaria "supérfluo ou destituído de qualquer significação. (2)

2. O enunciado do texto que, entre nós, vem das Constituições Republicanas anteriores (3), remonta, em sua aparição no Direito Público universal, a uma época na qual se terá tido em vista, realmente, o executor do direito. O Executivo, poderoso e absoluto, era então o poder a ser contido. Das Câmaras Legiferantes, porque essencialmente representativas do povo, não se suspeitava pudessem feri-lo com desigualdades iníquas.

A evolução do Direito Político, no entantơ, com o gradativo aperfeiçoamento das instituições constitucionais, fêz ver que cumpre resguardar o indivíduo contra a discriminação injusta, provenha ela de onde provier, pois o fato de um dos poderes do Estado ser menos tendente ao abuso não exclui que chegue a exorbitar. E então o princípio da igualdade se houve como limitação imposta aos diversos órgãos estatais, traduzindo-se o seu conteúdo, para o intérprete, na fórmula genérica de que o lei é iǵal para todos. Assim, aliás, a enunciava a Constituição Imperial. (4)

3. Tão vital se afigura o princípio da igualdade ao perfeito estruturamento do estado democrático, e tal é a sua importância como uma das liberdades públicas, para usar a clássica terminologia de inspiração francêsa, que, não obstante expresso como garantia conferida a "brasileiros e estrangeiros residentes no país" (5), o que denota, à primeira vista, ter tido em mira ape- 
nas as pessoas físicas, se tornou pacífico, alcançar também as pessoas jurídicas.

Aquela referência, conquantơ restrita na sua literalidade, se há de entender como compreensiva de quantos sujeitos de direito, pessoas físicas ou jurídicas, pelo nascimento, pela residência ou pela sede, que é a residência (e, mais que isto, o domicílio) dos entes morais, vivam ou existam sob a jurisdição do direito positivo do Brasil.

4. Os preceitos, que as Declarações de Direitos referem, constituem cânones fundamentais de tôda a ordem jurídica em que se organiza o Estado. Aplicam-se, no que pertinente, conforme as circunstâncias e as pessoas, aos interêsses e relações jurídicas de qualquer natureza, que nascem sob a jurisdição territorial das respectivas Constituições.

As referências a "súditos do Reino" (Declaraçãơ Inglêsa de 1688), a "direitos do homem" (Declaraçâo Francêsa de 1789), a "todos os homens" (Declaração Francêsa de 1793), das primitivas Declarações de Direitos, se explicam pelo seu sentido histórico-político. Em épocas nas quais se desconhecia ao povo qualquer parcela de atuação política e se relegavam a plano inferior tôdas as suas aspirações, se concretizavam nelas o que seriam, para o tempo, direitos primários e essenciais à posição condigna da pessoa humana, do homem, enfim, no conjunto social. Constituiam, por isto, cartas do's direitos do homem. Assim nasceram e assim se transmitiram de uns povos a outros. Quando já diferentes as condições político-sơciais, e nessas cartas se definindo direitos que ultrapassam o limitado das declarações primitivas, guardam elas, na referência ao homem, aos nacionais, ao estrangeiro, uma vinculação com o passado, que, sem lhes restringir o alcance, encontra explicação nas origens históricas do estatuto jurídico do cidadão.

5. Outro entendimento conduziria ao absurdo, como teve oportunidade de demonstrar Rui BARBOSA, em tôrno da Constituição de 1891, pela negação, até ao nacional, em via oblíqua, de direitos peculiares seus, dêsses mesmos direitos que a Constituição lhe reconhece individualmente (pois o problema não diz apenas com o princípio de igualdade, senão com todos os denominados direitos individuais), desde que the adviessem como partícipes de pessoa jurídica. Protegido o homem, mas não protegidas as pessoas jurídicas que criasse, o usar de um dos direitos assegurados na Lei Suprema - o direito de associação - acarretar-1he-ia, enquanto para aquelas levasse o cabedal dos seus bens e do seu esfôrço, o risco do arbítrio indiscriminado e sem limites do legislador e até da Administração Pública. (6)

Mas não só a êsse absurdo chegar-se-ia. Também a outros como, por exemplo, o da admissão de quaisquer restrições, mesmơ do confisco sôbre a propriedade de estrangeiros não residentes no Brasil e de sociadades estrangeiras aqui operantes. Não beneficiados pelas garantias constitucionais, tôdas as restrições e espoliações lhes poderiam advir de atos do Congresso. Para uns e outras, tantas vêzes chamadơs à cooperação em vultosos empreendimentos de interêsse nacional, o estatuto jurídico seria ditado pela vontade oscilante do legislador ordinário. Flutuaria segundo as tendências inspiradoras das renovações periódicas do Congresso. 
Daí porque PonTES DE MIRANDA, ante o imperativo de não constranger a proteção constitucional à estreiteza literal da fórmula - brasileiros e estrangeiros residentes no país - vale-se do conceito de garantia institucional:

"há preceitos que independem da afirmação inicial sôbre cidadãos e estrangeiros residentes no Brasil, e independem pela própria natureza das coisas: são as garantias institucionais; e as garantias institucionais são desligados da subjetividade eventual".

6. O problema da equiparação das pessoas jurídicas às pessoas físicas, diante dos textos constitucionais, encontra autorizado subsídio e solução feliz na jurisprudência e no direito norte-americanos. A sua evolução se prơcessou, na frase de HUGH EVANDER WILLS, pela prevalência do poder da razão sôbre o poder da forma (8). A princípio, não se equiparava a pessoa jurídica ao indivíduo para qualquer efeito. Estando previsto na Constituição Americana (como nas nossas ao tempo da dualidade de justiça), que os pleitos entre cidadãos de Estados diferentes seriam ajuizados na Justiça Federal, não se admitia, entretanto, que uma pessoa jurídica (corporation) acionasse perante os juízes da União, ou perante êles viesse a ser demandada, quando a outra parte fôsse pessoa domiciliada em Estado diferente daquele no qual tinha sede. A pouco e pouco, porém, se foi reaginda aos inconvenientes e ao ilogismo dêsse apêgo à literalidade do texto. Em caso no qual todos os acionistas de uma sociedade eram cidadãos do Estado onde a mesma se constituira, e a outra parte era cidadã de Estado diferente, considerou a Suprema Côrte se dever levar em conta que, por trás da sociedade, como ser fictício, artificial unit, estavam as pessoas dos sócios. E admitiu a jurisdição federal. Já numa segunda demanda foi mais longe o critério jurisprudencial. Tratava-se de sociedade da qual alguns acionistas eram naturais do mesmo Estado de que era cidadão o outro litigante. A Côrte Suprema houve como cabível a jurisdição federal porque, para os fins da cidadania de que falava a Constituição, todos os sócios se deviam haver como cidadãos do Estado onde tinha domicílio a sociedade. Assim, o pleito se armava entre cidadãos de Estados diferentes. $\mathrm{E}$ mais. Assentou que essa presunção era absoluta, não admitindo nem afirmação, nem prova em contrário ("no averment or evidence to the contrary is aumissible"). Hoje se considera, sem descrepância, que o ente moral "é, êle mesmo, cidadão do Estado onde se constituiu", para os "fins da diversidade de cidadania".

Por tal forma se ampliou a compreensão dos textos às corporations que, segundo WILLS, há julgados onde se pressupõe o direito delas até às liberdades de palavra e de imprensa. (10)

Do mesmo modo se tiveram como abrangidas as pessoas jurídicas, inclusive estrangeiras, pelas cláusulas de igualdade perante a lei e due process of law, instituídas em têrmos tais (com referências a cidadãos, a pessoas, à vida e a liberdade), que uma exegese literal faria supor alcançassem apenas as pessoas físicas. Considera-se que uma pessoa jurídica estrangeira (foreign corporation), uma vez autorizada a operar no país, fica habilitada à igual proteção das leis, bem como ao mesmo tratamento dispensado às pessoas jurídicas nacionais (domestic corporation). (11) 
7. Mas não só nos Estados Unidos se tem as pessoas fictas, em geral, como usufruindo estatuto jurídico equivalente ao das pessoas naturais, inclusive no que diz com o direito à igualdade de tratamento pela lei e em face da lei: SANTi Romano, estudando o princípio da igualdade no direito do seu país, considera que êle se estende "também às pessoas jurídicas, se a sua capacidade não fôr determinada de modo particular": (12)

A regra é a extensão, salvo restrições expressas da lei ou do ato, que autorize a sua constituição.

E MENOTTI DE FRANCESCO, no "Nuovo Digesto Italiano", atribui às pessoas jurídicas a mesma capacidade das pessoas naturais, quer nas relações de direito privado, quer nas de direito público, trate-se de direitos subjetivos, trate-se apenas de interêsse (verbete Persona Giuridica, n. ${ }^{\circ} 20$ ).

8. Há um acórdão do Supremo Tribunal em que se exclui a aplicação do princípio da isonomia a estrangeiros habitando no exterior, por aludir o texto constitucional apenas às "pessoas residentes dentro do território nacional". Nêle se defende até a legitimidade moral e política da tributação discriminatória entre residentes no país, naciơnais ou não, e estrangeiros residentes no exterior, no que há certa razão. (13) Afigura-se-nos, entretanto, que a simples residência no estrangeiro cria uma diferença de situação entre os que lá residem e os aqui radicados, que dispensa cogitar do princípio de igualdade. Mas quando assim não fôsse, seria de considerar a inaplicação dơ princípio pela sua própria natureza. O seu sentido é de garantia aos que se põem sob a bandeira do país, usufruindo as vantagens decorrentes da participação na vida do Estado brasileiro (política, social, econômica) e sujeitos, em contrapartida, aos ônus que a todos ałcançam, numa comunhão de trabalho, de sofrimentos, de ação, de interêsses. Não há, pois, como beneficiar, com o seu alcance, os que estão fora da comunhão brasileira.

9. Enquanto para o administrador e o juiz, a aplicação do princípio se simplifica, porquanto, no que diz respeito à execução, cabe, apenas, a fim de torná-lo efetivo, não executar u'a mesma regra legal de modo diferente para situações iguais, em relação ao legislador ela se arma de maior complexidade. O critério da igualdade há de ser encarado a dois ângulos diferentes, conforme atue através de leis materiais ou formais.

10. Quando o legislador edita normas de conduta, gerais e abstratas (leis em sentido material), o que the cumpre é, dentro delas, não dispensar vantagens ou criar ônus para pessoas ou relações, que estejam, pela sua posição ou configuração, em pé de igualdade. O princípio significa para êle que, ao elaborar a lei, deve reger, com iguais disposições - os mesmos ônus e as mesmas vantagens - situações idênticas, e, recìprocamente, distinguir, na repartição de encargos e benefícios, as situações que sejam entre si distintas, de sorte a aquinhoá-las, ou gravá-las, em proporção às suas diversidades.

Traduz-se a isonomia numa proporção da justiça, de que LuIz SANChes AGESTA aponta, como expressivo exemplo, $\alpha$ da moderna legislação do trabatho, favorecendo o empregado e onerando o empregador, pela consideração da debilidade econômica e social daquele ante êste. (14) Se o legislador ela- 
bora uma lei, na qual discrimina entre pessoas que estão, pelas suas atividades, posições, etc., em pé de igualdade, afasta-se do princípio da isonomia; fere-o. Quando diante de pessoas ou circunstâncias diferentes, reparte desproporcionalmente às suas diversidades, gravames ou favores, também atenta contra êle. Advirta-se, de passagem, que ali é muito mais fácil identificar o atentado à igualdade do que aqui, pois a identidade é mais fàcilmente constável do que a proporção devida entre situações desiguais. Por isto SorIano DE SOUZA ponderava que se "é fácil compreender e admirar o valor intrínseco do princípio da igualdade civil, não é tão fácil a sua aplicação, nem a sua conciliaçãa com as desigualdades das capacidades individuais".

11. A tarefa legislativa, no caso das leis materiais, se afigura, em princípio de fácil desempenho. Considerando, simultâneamente, um conjunto de situações, o legislador só distinguirá entre as que forem idênticas por deliberado propósito, ou por gritante êrro de técnica.

12. Qualquer elemento de fato, que leve a diversificarem entre si, ainda que mìnimamente, duas situações, afeto o critério do igual tratamento. Para que êste haja necessàriamente lugar, é preciso tratar-se de situações que se possam justapor, com exatidão, pelas suas características materiais.

Assim é que o usufruto e o fideicomisso podem ser tributados diferentemente, sem embargo da semelhança que guardam as situações dos respectivos beneficiários, pois entre êsses institutos há analogia, mas não identidade. (16)

Na que diz, por exemplo, com os cargos de carreira no serviço público, näc é possível, atentar a natureza e a estruturação das carreiras, pretender a igualdade de remuneração, apenas porque idênticas as funções e as responsabilidades. A hierarquia dos padrões de vencimentos obedece, então, a critério que, não sendo o da identidade dos deveres, da competência, etc. é, no entanto, bastante para ensejar distinguir entre servidores. E' o critério da maior permanência no serviço (promoções por antiguidade) ou o do melhor desempenho da função (promoções por merecimento). (17)

A simples diversidade de critérios na investidura também afasta a obrigatoriedade de igual tratamento. (18)

$\mathrm{Na}$ verdade, uma investidura que obedece a exigências mais sérias, inclusive concurso, coloca o servidor funcionário em situação diferente da daquele, que logrou ingresso no serviço público pela via sumária do contrato, às vêzes sem sequer indagações sôbre a sua habilitação (extranumerário). Às maiores exigências de admissão pode corresponder, e de modo geral deve mesmo, um tratamento melhor quanto à remuneração e estabilidade.

13. O Supremo Tribunal admitiu que a diversidade das regiões onde habitam os atingidos pela lei, justifica a desigualdade de tratamento por parte do legislador. Conquanto em tese tal seja possível, pois muito diversas as condições geo-econômicas em que atua a lei, num país tãơ vasto como o nosso, hão de surgir situações nas quais a desuniformidade das condições de vida justifique a diferenciação dos critérios legais, a exceção deve ser acolhida com a maior cautela. Até porque será raro, raríssimo, que isso possa ter lugar, pois 
uma das pilastras mestras da Federação está, exatamente, na igualdade jurıdica e civil, de quantos vivem sob a bandeira da União. (19)

14. Quando o legislador é induzido, pelas circunstâncias, à edição de leis formais, o problema se mostra de mais delicada colocação. Excepcionalmente, pode mesmo se tornar carente de objetivo a aplicação do princípio.

15. Havendo lei material sôbre um assunto, a ela fica o Congresso adstrito, no dispor sôbre situação que, não obstante regulada por ato legislativơ individualizador, caia no âmbito da lei disciplinadora de situações idênticas. Já não se encara o respeito à igualdade em face da Constituição diretamente, e sim diante das leis materiais, que, abaixo da Carta Magna, regulam as atividades, não só dos Pơderes Executivo e Judiciário, como também do próprio Poder Legislativo. Não é permitido ao legislador, sem violação do princípio da isonomia, ignorar a lei geral para regular, à revelia do seu texto, situações que ela alcança, ao lado de outra ou doutras. Não é possível ao Poder Legislativo, sem ferir o princípio da igualdade, dispor de modo especial, sôbre uma determinada situação, distinguindo-a, desfavoràvelmente, em comparação com as demais idênticas, gravando-a, em suma, de modo particularmente mais oneroso. O que the compete quando se desenha caso, no qual há de praticar ato legislativo (formal) de individualização (e isto ocorre excepcionalmente, pois a função individualizadora do direito positivo é partinente, via de regra, aos Poderes Executivo e Judiciário), é praticá-lo atendo-se às normas gerais, que, num outro ato seu (lei material) se traçaram. A sua posição não difere da do administrador quando, na rotina da sua atividade, individualiza situações jurídicas. Tanto quanto êste, deve aquêle resolver uma situação determinada, ajustando-a aos textos normativos preexistentes. Não the é lícito passar por cima da regra geral, a que êle próprio quis submeter uma série de casos. Impõe-se então considerar, para resguardo do critério da igualdade, de um lado a posição da pessoa ou relação jurídica afetada pelo ato legislativo, e de outro a das pessoas ou relações que a êsse ato possam escapar, embora idênticas àquela. Quer para não gravar, quer para não favorecer a um só, deixando outros em situação possìvelmente idênticas, fora do alcance do ônus ou benefício instituído.

16. Inexistindo lei material, mas tendo o Poder Legislativo diante de si, a pedir solução, caso identificável com outros de possível ocorrência, tocalhe, para não fugir ao princípio da isonomia, criar normas que, resolvendo êsse caso emergente, se prestem ao enquadramento daqueles outros de configuração possivel e eventual. Não no fazendo, estará, pelo menos, dando lugar a que situação idêntica surgida de futuro, não encontre na lei os caminhos abertos à situação anteriormente cogitada e resolvida por uma solicitude unilateral. E não será fora de propósito, que o titular do direito descurado ou preterido pela omissão do legislador, possa invocar, em via jurisdicional, tratamento idêntico ao que, se genéricơ o texto por êsse elaborado, já o estaria beneficiando.

17. Quando se esteja diante de situação singular, única, com respeito à qual não exista norma reguladora, já aí é possível ao legislador dispor tão sòmente sôbre ela. O que é preciso é que as circunstâncias mostrem que, 
realmente, só de tal situação se poderia cơgitar. Então a lei que elaborar será rigorosamente formal, pois só terá o nome de lei porque emana de órgão legiferante.

18. Para o administrador há sempre uma lei a aplicar, ainda que por analogia, de sorte que o caso singular em suas mãos será aquêle que, embora único cơmo ocorrência na prática diuturna da Administração Pública, na legislação se previu, mais ou menos claramente, pudesse surgir ao lado de outros. O que the cabe, por conseguinte, é, independente dessa singularidade, a êle aplicar - como a outros também aplicaria, se outros iguais houvesse a lei adequada.

Para o legislador o caso singular é aquêle que exige norma especial para a sua solução, por nenhuma haver, capaz de resolvê-lo entre as já existentes. Cabe-lhe, ou deixar à Administração aplicar essa norma especial, ou adiantar-se no executá-la, individualmente, desde logo, a situação visada. Ȧ Administração Pública ficarão, nesta última hipótese, apenas providências cơmplementares de aplicação isto é, de individualização imediata.

19. Senđo tal a situação, não há cogitar de aplicação do princípio da isonomia. Especial e única a situação, nenhuma havendo a se confrontar com ela, não há, como falar de tratamento desigual. A lei formal, destinada a reger um caso assim específico, que, portanto, pela sua configuração mesma, escapa ao confronto com outros, tem de ser encarada levando em conta essa singularidade.

Os conceitos de igualdade e de desigualdade são relativos, impõem a confrontação e o contraste entre duas ou várias situações, pelo que onde uma só existe não é possível indagar se houve tratamento igual ou discriminatório. Desde que "a discriminação já é um dado de fato, a lei que reconhece a diferença, para tratar cada caso de acôrdo com a sua natureza específica, não está, efetivamente, discriminando". (20) Poderá haver, aí, tratamento benevolente, justo ou rigoroso, mas não privilegiado ou discriminatório.

20. E' certo que muito dificilmente se podem figurar situações assim isoladas sem similar, tão reiterados são, geralmente, os fatos econômicos e sociais com que lida o Estado. A prática, entretanto, mostra que podem ocorrer. (21)

Por isto SANTIAgo DANTAS, num ensaio meritório, ("Igualdade perante a Lei e due process of law"), sem embargo de ressaltar o perigo das iniquidades oriundas de tratamento específico por parte do legislador, admite que êste por vêzes se impõe e justifica:

"Essa diferenciação, muitas vêzes se justifica e satisfaz a conveniência jurídica."

Reconhece, outrossim, que "a política econômica do Estado moderno não dispensa as medidas legislativas de exceção, que vêm submeter o tratamento diverso casos compreendidos na mesma norma geral". (22)

E o Supremo Tribunal já houve ocasião de decidir, sôbre voto do preclaro Orozimbo Nonato, que tendo o princípio da isonomia, como finalidade, "impedir privilégios e distinções por motivos desligados do interêsse comum", não constitui obstáculo à "elaboração de jus speciale". (23) 
21. Dir-se-á que, configurada uma situação específica, o Poder Legislativo, para não legislar discriminatòriamente, diante do caso singular deve prever a sua multiplicidade e construir embora êle seja um só, regras que, alcançando-o, possam, ao mesmo tempo, servir para o enquadramento de situações hipotéticas, de situações imaginadas para o futuro. Dêsse modo procedendo, não distinguiria essa situação daquelas em que o caso a resolver não é único por sua natureza, mas apenas eventualmente, porque outros iguais ainda não ocorreram. Afigura-se-nos, entretanto, que o princípio constitucional da isonomia não deve ser levado tão longe, de modo a transplantar-se do domínio objetivo para o das abstrações e das hipóteses, que a prática da vida repele. O que com êle se quer é evitar a iniquidade de dois pesos e duas medidas. Se isto não está em jogo, parece demasiado que, por um artifício, se imagine u'a multiplicidade de situações, só para admitir em teoria a sua aplicação, quando efetivamente inexiste oportunidade para de tais situações cogitar.

22. O princípio da igualdade, ainda mal explorado nas suas repercussões jurídicas sôbre os atos do Poder Legislativo, muito pode contribuir à proteção do indivíduo contra a discrição do legislador, e, também, ao aperfeiçoamento da ordem legal sob a supremacia da ordem constitucional. A êle está reservado, sem embargo das dificuldades que muita vez a sua aplicação suscita, um papel relevante na preservação dos direitos individuais e do interêsse público contra atos arbitrários do órgão legiferante.

Quando êstes firam direitos subjetivos do indivíduo, a invocação do critério de igualdade terá lugar através da via processual que, conforme o tipo de lesão; se torne adequada (mandado de segurança, ação cơminatória, ação condenatória, etc. ) Em tais casos, a demanda seguir-se-á, quase sempre, o ato administrativo de aplicação da lei inconstitucional. Só, por exceção, quando o próprio ato legislativo (caso de lei formal exequível sem interposição de medida administrativa) acarrete diretamente a lesão de direito, será de atacá-lo em si mesmo. Êle participará, então, da natureza legislativa pela origem e da administrativa pelo conteúdo e porque na essência ato administrativo, isto é, determinante ou definidor de situação jurídica individual, o Poder Judiciário o pade apreciar de imediato.

Em se tratando de ato legislativo que, ao desprezar o princípio da igualdade, não fixa direito subjetivo do indivíduo, mas lese o patrimôniơ da União, de algum Estado ou Município, de alguma entidade autárquica ou sociedade de economia mista, o remédio adequado para atacá-la judicialmente, é a ação popular. E a qualquer cidadão fica a faculdade de propô-la. (24)

\section{NOTAS BIBLIOGRÁFICAS}

(1) "Todos são iguais perante a lei", art. $141, \S 10^{\circ}$

(2) Francisco Campos, Parecer, Revista Forense", vol. 116, pág. 396.

(3) 1891 , art. $72, \& 2 .^{\circ} ; 1934$, art. 113, n. ${ }^{\circ} 1 ; 1937$, art. 122, n. $^{\circ} 1$.

(4) Art. 179, n. ${ }^{\circ} 13$.

(5) Art. 141, caput.

(6) Comentários à Constituição Federal Brasileira, coligidos e ordenados por Homero PIREs, vol. V, págs. 197-203. 
(7) A Constituição Federal de 1946, ed. Cahen, vol. III, pág. 164.

(8) The power of reason haas prevailed over power of ritual, Constitucional Law of the United States, ed. Principia Press, pág. 849.

(9) WILLS, ob. cit., págs. 848-856; W. W. WILloughBy, Constitucional Law, edição Baker, Woorhis \& Companhy, vol. II, págs. 882-884, 984-986; BromaGE, Etate Government and Administration in the United States, ed. Haper \& Brothers, pág. 321.

(10) Ob. cit., págs. 856-857.

(11) Corpus Juris, volume 14-A, \$ 3.950; Wrlls, ob. cit., pág. 853.

(12) Corso di Diritto Constituzionale, $4 .^{\mathrm{a}}$ ed., pág. 153.

(13) "Revista Forense", vol. 67, págs. 74-5.

(14) Lecciones de Derecho Politico, 1951, pág. 560.

(15) Principios Gerais de Direito Público e Constitucional, 1893, pág. 408.

(16) Supremo Tribunal Federal, em 23-8-934, sôbre voto do ministro Arthur Ribeiro, "Revista Forense", vol. 67, págs. 74-5.

(17) O Tribunal Federal de Recursos já assentou, acolhendo voto do juiz Elmano Cruz, em ação na qual contadores do quadro ordinário do Ministério da Fezenda pretendiam equiparação aos do quadro complementar:

"O princípio da isonomia deve ser aplicado com tôda a cautela no tocante a cargos de carreira, pois nestes cargos de carreira, embora as funçōes sejam iguais, as remunerações são necessàriamente diferentes. Assim um oficial administrativo letra $\mathrm{J}$, exerce as mesmas funções do oficial administrativo letra $\mathrm{K}$, embora diversamente remunerados." (Ap. 3.843, "Diário da Justiça" de 4-8-53, Apenso ao n. ${ }^{\circ} 177$, pág. 2.196”.

(18) Assim decidiu o Tribunal Federal de Recursos, na apelação civil n. 3.447 , relatada pelo juiz MOURÃo RUSSELL, para afastar equiparação pretendida entre funcionário e extranumerário ("Diário da Justiça"" de 4-8-53, Apenso ao n. 177, pág. 2.191).

(19) Aliás, no caso do acórdão citado se nos afigure, data vênia, ser menos defensável o tratamento diferencial. Foi êle prolatado a propósito do art. 894 da Consolidação das Leis do Trabalho. Esse dispositivo institui o recurso de embargos, para o próprio juízo prolator da sentença, como o recurso de que se poderá valer o interessado no caso de decisões definitivas das juntas e juízes em dissídios individuais relativos a salários, férias a indenizações conseqüentes de rescisão de contrato. E toma por base o valor do pedido e as regiões onde ajuizado, de sorte que o recurso será cabível, em umas circunscrições terri. toriais, se a reclamação tiver o valor máximo de $\operatorname{Cr} \$ 150,00$ (Municípios do interior do Acre, Amazonas, Pará, etc.), em outras se êsse valor chegar a $\operatorname{Cr} \$ 300,00$ (Municípios das capitais do Acre, do Amazonas, Pará, etc., e do interior do Ceará, de Pernambuco, da Bahia, etc.) a Cr\$500\$00 (Municípios do interior do Estado do Rio e de São Paulo). a $\mathrm{Cr} \$$ 600,00 (Municípios das capitais do Ceará, de Pernambuco, etc.), e, finalmente, a Cr\$ 1.000,00 (Distrito Federal e capitais do Estado do Rio e de São Paulo). (Agravo n. 13.234 , "Revista Forense", vol. 118, pág. 426-9). Ora, isso implica em tratar diversamente os habitantes de diferentes Municípios do país, a propósito de relaçôes jurídicas de igual natureza. Nem a razão que sempre justificou a jurisdição por alçada - a menor importância econômica, para os interessados e a coletividade, dos pleitos de menor valor pecuniário - explica a distinção. Aqui êsse critério é invertido. Se maior o valor da reclamação e, consequientemente, mais importante ela para o reclamante, menos possibilidade terá êle de recorrer. O critério foi, por conseguinte, puramente geográfico, e a Constituição o veda no art. $31, \mathrm{n} .^{\circ} \mathrm{I}$, que no seu amplo alcante, atinge também o tratamento desigual à base do domicílio ou da residência. Acentue-se que a proibição de discriminação de cunho estritamente geográfico exurge doutros textos da Lei Magna (arts. 17, 27 e 32), o que bem se explica como um imperativo da organização política federal. 
(21) Em matéria de desapropriação por utilidade pública, declarada por ato do Poder Legislativo Federal, há dois casos, de que, não faz muito tempo, tivemos oportunidade de nos ocupar, os quais, comparados, servem ao esclarecimento de quanto se vem de expor.

Um dêles diz com a desapropriação de imóvel de propriedade do Banco Francês-Italiano para a América do Sul, o outro concerne ao expropriamerıto das ações do Banco Hipotecário e Agrícola de Minas Gerais.

No primeiro caso a União, por um ato legislativo - o decreto-lei n. ${ }^{\circ} 5.992$, de 12 de novembro de 1943 - desapropriou (nêle se fala de incorporação ao patrimônio nacional) um imóvel na Capital da República, fixando-lhe o preço, que, ao invés de ser depositado ou. pago antecipadamente, foi creditado ao Banco, então em liquidação forçada conseqüente da legislação de guerra.

Ora, a expropriação de imóveis era regulada, a êsse tempo, como ainda o é hoje, por uma lei geral sôbre desapropriação - decreto-lei n. ${ }^{\supset} 3.365$, de 21 de junho de 1941 sendo mesmo os imóveis os bens de que trata por excelência (art. 27 e parágrafo único e art. 37).

Dela abstrair num caso determinado, para tornar um só imóvel sujeito a processo especial de apropriação forçada pelo Estado, com posse imediata, sem o depósito prévio que a lei prevê (art. 15), com fixação do preço pelo próprio interessado - a União - e não mediante acôrdo ou processo contencioso, como também previsto na lei (art. 10), é discriminar, sem dúvida, flagrantemente, pois é dar tratamento de exceção a uma situação igual a centenas de outras situações. Enquanto em todo o país, diàriamente, ao ter de usar o poder de expropriamento, a União Federal (para não falar dos Estados e Municípios) chama o proprietário a juízo, pede à Justiça a imissão provisória na posse, fazendo para tal um depósito estipulado em lei, e debate perante o Poder Judiciário, em duas instâncias, pelo menos, o valor de indenização, só após pagá-lo se convertendo em proprietária dos bens do seu interêsse, nesse caso faz de parte e de juiz, declara a utilidade e fixa o preço. prescindindo de todo o formalismo naqueles religiosamente obedecido. Nenhuma discriminação mais palpável.

No cáso do Banco Hipotecário e Agrícola as coisas se passaram de modo diferente. A União, pelo decreto-lei n. ${ }^{\circ} 6.953$, de 12 de outubro de 1944 , considerou-o, e às respectivas ações, como de utilidade pública, para os efeitos previstos na Lei de Desapropriação (art. $1^{\circ}$ ), autorizou o Govêrno do Estąo de Minas Gerais a expropriar as ações referidas (art. 2..$^{\circ}$, e, por fim, atribuiu a cada uma destas o valor resultante da divisão do ativo líquido constante do último balanço publicado pelo número total das que estivessem em çirculação (art. $3^{\circ}$ ). Com assim proceder adotou providências especiais, abstraindo da lei gerail preexistente - o decreto-lei n. ${ }^{\circ} 3.365$, de 21 de junho de 1941. Mas na Lei de Desapropriação inexiste qualquer referência aos bens que se queria expropriar - ações de sociedade mercantil. A desapropriação de valores dessa ordem era inédita no país e não se cogitava de fazê-la uma operação usual, pois sòmente circunstâncias especiais induziam a chamar ao patrimônio público a gestão de um estabelecimento bancário vital à economia de certo Estado da Federação. Inclusive algumas relacionadas com a anormalidade que no momento acometia o Mundo - a Segunda Grande Guerra - donde resultava que muitos portadores de ações, residindo em país conflagrado, escapavam a qualquer possibilidade efetiva de sujeição às leis e aos órgãos administrativos ou, jurisdicionais brasileiros. Não havia conflito, a legislação portanto, em princípio, entre a legislação específica (lei formal) e a genérica (lei material). O assunto trotado naquela escapara à regulaçáo por esta. Enquanto isso a ei de Desapropriação, no art. 27, recomendava ao juiz, como bases preferenciais à fixação do preço de coisa expropriada, critérios inaplicáveis, com propriedade, à fixação do valor de ações das sociedades anônimas. Os únicos três elementos que delas se podiam inferir, ajustáveis à estimação do preço de ações - valor para efeitos fiscais, preço de aquisição, interêsse auferido pelo proprietário - tornavam-se por vêzes inconciliáveis e, conseqüentemente, inexpressivos como dados a articular para o levantamento do quantum a ser indenizado. Era o que sucedia, por exemplo, com a tributação, que, na falta de oportuna cotação dos títulos em bôlsa, devia incidir sôbre o seu valor nominal (decreto-lei n..$^{\circ} 4.655$, de 3 de setembro de 1942, tabela anexa, art. 43, nota $2 .^{a}$ ), o qual, como em regra ocorre, não correspondia ao preço de aquisição. Também o decreto- 
lei especial não retirava ao Poder Judiciário a atribuição de fixar o valor da indenização da coisa expropriada, que na Lei de Desapropriação the é cometida. O que nêle se fazia eı vincular essa competência a um certo critério - o da divisão do ativo líquido, constante do último balanço, pelo número de ações integrantes do capital. Dentro dêsse critério legal ficava a Justiça, examinada a prova e ponderadas as objeções que se levantassem quanto ao conteúdo dela e à sua validez, acertar o preço a ser pago por ação.

Por outro lado não havia por que reger, de modo geral, a desapropriação de ações de sociedades bancárias. Do ponto de vista do interêsse público era até desaconselhável fazê-lo. A lei específica encontrava explicação num critério de prudência do legislador. Assim é que, não havendo o propósito de expropriar ações em geral, de sociedades anônimas entregues ao comércio bancário, mas ocorrendo apenas a necessidade de chamar à propriedade do Estado, por circunstâncias especiais, o acêrvo de um só estabelecimento, porque só êle gerido de modo considerado nocivo à economia coletiva, uma lei que, para predispor a essa medida específica, admitisse, em tese, a desapropriação de estabelecimentos bancários, traria a inquietação e talvez o pânico a um setor importante da economia do país. Nela supor-se-ia estar o instrumento de uma nova política do Estado em relação ao crédito, possìvelmente a tenđência a monopolizá-lo, tudo acarretando incerteza e intranquilidade, quer à vida comercial, quer à produção, pelos reflexos das crises do crédito bancário sôbre elas.

Impunha-se, por conseguinte, regular especialmente o caso, por omissa a lei geral, e era até conveniente que sòmente dêle se tratasse, de vez que perigosa a regulação de situações assemelháveis.

Admita-se, semelhantemente, que circunstâncias excepcionais levassem a União a considerar imperioso incorporar ao seu patrimônio, para dela dispor no interêsse coletivo, a fórmula de um produto farmacêutico. Não previsto na Lei de Desapropriações o expropriamento de bens dessa natureza, far-se-ia mister ato do Congresso a respeito. Porém, numa tal hipótese, dizer expropriáveis as formulas farmacêuticas, em geral, e tarçar regras às respectivas indenizações, ou simplesmente instituir, dentro do sistema do Decreto-lei número 3.365 , de 21 de junho de 1941 , mais um caso de expropriamento, que as abrangesse, seria deixar tôda a indústria de drogas sob ameaça potencial de desapropriação do objeto de sua atividade, e, ademais, sujeitar as fórmulas expropriáveis a um inviável processo de avaliação. Impor-se-ia, pois, como um critério mais justo e cauteloso, afetar, por ato legislativo, apenas a fórmula e o proprietário visados, prevendo, ao mesmo tempo, bases especiais para a aferição do desfalque patrimonial conseqüente. O legislador ao estabelecer critério peculiar para êsse caso, também peculiar, não estaria discriminando, mas tão sòmente dispondo, em espécie, para o que só em espécie seria de dispor.

Vê-se, por êsses exemplos, como é delicado, na prática, conter o legislador, no uso do poder de legislar para casos singulares, dentro de cânones engendrados a priori, a fim de preservar a igualdade de todos perante a lei.

Aliás, as duas situações descritas, tão caracteristicamente diversas no seu conteúdo jurídico, ensejaram, da parte de interessados no desate do caso do Banco Hipotecário, uma deturpação do nosso pensamento no caso do Banco Francês e Italiano, com o propósito de convencer de que opináramos contraditòriamente, sustentando naquele, ponto de vista que não fôra o mesmo exposto neste outro (Memorial dos ex-acionistas do Banco Hipotecário, subscrito pelo Dr. Dario de Almeida Magalhães). Para lograr o seu objetivo, o ilustre patrono do Banco (após classificar de ǵrosseiro sofisma a asserção, que fizéramos, a propósito do expropriamento das ações bancárias, de que supondo o princípio da igualdade uma relação entre pessoas ou situações, não há como o levar em conta quando se trata de caso singular, insuscetível de confronto com outro qualquer) teve de isolar trechos do nosso primeiro parecer e confrontá-los com trechos, igualmente insulados, do segundo. Trechos em que transpareciam conceitos gerais compatíveis com ambos os casos. Um expediente de defesa. Mas um deplorável expediente...

(22) Problemas de Direito Positivo, 1953, págs. 37-38.

Agrr. de petição n. ${ }^{\circ}$ 13.234, "Revista Forense", vol. 117, págs. 426-429.

Constituição Federal, art. 141, § 38 . 


\section{SUMMARY}

1. The constitutional principle of juridical equality binds not only the administrator and the judge, but also the legislator.

2. Historically, the principle aimed at protecting the individual against discrimination from the executive power. It has evolved, however, to cover in its scope also the legislative.

3. The principle also protects juridical persons, although its formal wording refers to "Brazilian and foreign residents".

4. The principle embodied in the several declarations of rights. Reference to the British Declaration of Rights of 1688, and to the Frewch Declaration of Right of 1793 . Analysis of the spirit such declarations.

5. The construction of the principle as restricted to the individual would be absurd, as demonstrated by RUY BARBOSA as regards the Constitution of 1891. It would place the juridical persons at the discretion of the Executive and the Administration. The opinion of PONTES DE MIRANDA also against the restricted litteral interpretation of the phrase "Brazilian and foreign residents".

6. The problem of the equivalence of the juridical and natural persons in the Constitution: the felicitous contribution of American law and jurisprudence. "The power of reason has prevailed over the power of ritual (JUGH EVANDER WILLS, Constitutional Law of the United States. Historical development of the institution from its beginnings. Recognition that, behind the corpcration, an artificial unit. lies the individual. Both domestic and foreign corporations entitled to equal legal protection of their rights.

7. Equality of juridical and natural persons before the Italian law as the Beneral principle. Restrictions to the said principle expressly declared by law. Santi Romano and Menotti de Franceco quoted on the matter.

8. The decision of the "Supremo Tribunal" (Brazilian), which excludes the application of the isonomy principle to foreigners living abroad. The Author's opinion on such discrimination.

9. The application of juridical equality involves no special difficulties for the administrator or the judge. With respect to the legislator, however, the principle has two approaches which correspond to (1) material laws and (2) formal laws.

10. In case of material laws - general, abstraat legal norms, the principle of juridical equality should be expressed in terms of proportion of justice.

10. Given a set of situations, in case of material laws, the legislator should distinguish those which are identical because of (1) deliberate purpose of (2) technical errors.

11. Any factual elements which tend to distinguish two situations from each other infirms the principle of juridical equality. Such principle requires the existence of situations that are identical, according to their material characteristics. The Author illustrates his point with usucaption and fideicomissum, as well as with the careers in the civil service and the claim of aquel pay to equal duties and responsibilities.

12. The "Supremo Tribunal" (Brazil) has admitted that the diversity of regions where live those affected by the law justify the inequality of treatment on the part of the legislator. The exception, in the Autror's opinion, to be taken with utmost caution.

13. When formal laws are enacted, the problem is rather difficult on exceptional occasions, the application of the principle of juridical equality may even prove to be pointless. 
14. When there exists a material law regulating some matter, the Congress is bound to apply it ts regards any situation whichs falls within the scope of that law. The principle of juridical equality is approach not in terms of the Constitution proper hut rather in terms of the material law in question.

15. When no material law exists, and the Legislative is confronted with the necessity of solving a case identifiable with others of possible occurrence, it must, in order to obey the principle of isonomy, create norms which, solving the individual case, are liable to comprise possible future cases.

16. When the legislator is confronted with a unique situation, and no norm exists to regulate it, he may legislate for it.

17. There is always, for the administrator, a law to be applied. The unique case that might emerge means that, although being unique, the 1geislator has assumed that others might occur.

18. If the situation is that mentioned on item 17 , there is no room for the application of the isonomy principle. The application of a formal law that aims at regulating a specific case has to take into account that singularity.

19. Unique situations are of rare occurrence since the economic and social facts dealt with by the State are liable to repeat. Yet the economic policies of the modern State cannot ignore exceptional legislative norms.

20. Given a specific situation, the Legislative, in order to legislate discriminatorily, before a singular case, ought to foresee the possible repetition of it, and establish provisions that, covering the case, ought to foresee the possible future occurrence of it, and establish norms that, covering the case, might also provide for those possible future ones.

21. The principle of equality can greatly contribute towards the protection of the individual against the discretion of the legislator. It can also contribute for the development of leglal order under the supremacy of constitutional order.

O empirismo está passando a ser o distintivo, a marca de fábrica do administrador chambão, incapaz e estéril, produtor de desordem e sacrificador de programas, cuja ação, longe de se traduzir em realizações desejadas, gera o desperdício, a resistência passiva, a morosidade, a ineficiência e o parasitismo.

Benedito Silva 